\title{
Modelling of chloride penetration in concrete under wet/dry cycle
}

\author{
Sung-In Hong ${ }^{1}$, and Ki-Yong Ann ${ }^{1, *}$ \\ ${ }^{1}$ Hanyang University, Department of Civil and Environmental Engineering, Ansan, South Korea
}

\begin{abstract}
This present study concerns modelling of chloride penetration in partially saturated concrete. To mimic the intermittent exposure of sea water to concrete, varying environmental conditions for relative humidity and chloride concentration were considered. As for the moisture distribution in concrete, statistical permeability model based on pore size distribution was used to represent influence of material properties on moisture transport. Then, a combined chloride diffusion and convection was modelled in variation of moisture level in concrete. As a result, smaller relative wet duration induces higher rate of chloride penetration due to enhanced moisture permeability from the surface, and also higher concentration gradient near the surface of concrete due to repeated wet/dry cycle. This implies that only diffusion analysis on chloride induced corrosion in concrete structure may underestimate the serviceability in given material performance.
\end{abstract}

\section{Introduction}

Chloride penetration in reinforced concrete structure has been regarded as a big problem in the service life design. When chloride ions reach on the steel surface in concrete, a passive film, maintained by a high alkalinity of concrete pore solution, starts to dissolve, thereby leading to corrosion of steel [1]. Corrosion propagation accordingly imposes cover cracking of inner part of concrete, which in turn gives rise to a structure failure in the end of the deterioration process. Thus, predicting the chloride ingress in concrete structure exposed to a saline environment is essentially required to prepare a proper maintenance and thus reduce such high risk of chloride induced corrosion.

For this purpose, many of modelling works have been carried out based on the Fick's law of chloride diffusion. However, most of concrete structures, built in chloride laden environment such as the bridge pier with tidal zone and load pavement with deicer supply, have been experiencing intermittent chloride exposure. Moreover, those conditions, compared with the case for constantly immersed structure in saline water, impose more severe degradation to the concrete durability $[2,3]$ and difficult to be assessed by using only the conventional diffusion analysis.

This study aims to develop a model for predicting chloride transport in concrete, submitted to intermittent chloride exposure. In this paper, the driving force of chloride ions

\footnotetext{
* Corresponding auther: kann@hanyang.ac.kr
} 
transporting in partially saturated concrete was defined as diffusion-convection phenomena. To investigate the combined transport mechanism in concrete under wet/dry cycle, moisture distribution, considering a statistical approach on permeability and hysteric effect on water vapour adsorption and desorption, was first addressed, and then chloride diffusion through water filled porosity and chloride convection driven by moisture flow were analysed.

\section{Model description}

\subsection{Moisture distribution}

Prior to solving the chloride diffusion-convection problem in concrete, moisture distribution under equal environmental condition with chloride source should be analysed. Under thermodynamic equilibrium in concrete, moisture transport, driven by permeation of both liquid and vapour through concrete pore network, can be described using the onedimensional mass balance equation such as:

$$
(d w / d h) \cdot(d h / d t)=\operatorname{div}\left[\left(K_{1} \cdot \rho_{\mathrm{w}} \cdot R \cdot T\right) /\left(M_{\mathrm{w}} \cdot h\right) \cdot \operatorname{grad}(h)+K_{\mathrm{v}} \cdot P_{0} \cdot \operatorname{grad}(h)\right]
$$

where, $w$ is the moisture content $\left(\mathrm{kg} / \mathrm{m}^{3}\right), h$ is the relative humidity, $t$ is the time (s), $K_{l}$ is the permeability of the liquid water $(\mathrm{kg} / \mathrm{m} \cdot \mathrm{s} \cdot \mathrm{Pa}), \rho_{w}$ is the density of water $\left(\mathrm{kg} / \mathrm{m}^{3}\right), R$ is the gas constant $(\mathrm{J} / \mathrm{kg} \cdot \mathrm{K}), T$ is the temperature $(\mathrm{K})$, and $M_{w}$ is the water molecular weight $(\mathrm{kg} / \mathrm{mol}), K_{v}$ is the permeability of water vapour $(\mathrm{kg} / \mathrm{m} \cdot \mathrm{s} \cdot \mathrm{Pa})$, and $P_{0}$ is the saturation vapour pressure $(\mathrm{Pa})$. According to the statistical permeability model [4], liquid permeability was determined, considering pore size variation from zero size $(r=0)$ to the critical radius at capillary condensation $\left(r=r_{\mathrm{c}}\right)$, which is obtained by the Kelvin's law, such as:

$$
K_{1}=\rho_{\mathrm{w}} /\left(8 \cdot \tau^{2} \cdot \eta\right) \cdot\left[\int r_{\mathrm{eq}} \cdot \varnothing(r) \cdot d r\right]^{2}
$$

where, $\tau$ is the tortuosity factor, $\eta$ is the viscosity of liquid water $(\mathrm{Pa} \cdot \mathrm{s}), r_{\mathrm{eq}}$ is the equivalent pore radius $(\mathrm{m})$ [Chaube et al], $r$ is the pore radius $(\mathrm{m})$, and $\varnothing(r)$ is the cumulative porosity distribution, which in this study was defined by:

$$
\varnothing(r)=\varnothing_{\mathrm{G}} \cdot\left[1-\exp \left(-b_{\mathrm{G}} \cdot r\right)\right]+\varnothing_{\mathrm{S}} \cdot\left[1-\exp \left(-b_{\mathrm{S}} \cdot r\right)\right]+\varnothing_{\mathrm{L}} \cdot\left[1-\exp \left(-b_{\mathrm{L}} \cdot r\right)\right]
$$

where, $\varnothing_{\mathrm{G}}, \varnothing_{\mathrm{S}}, \varnothing_{\mathrm{L}}$ are respectively the porosity for gel, small, and large capillary pores, and $b_{\mathrm{G}}, b_{\mathrm{S}}, b_{\mathrm{L}}$ are respectively the distribution parameters for gel, small, and large capillary pores. As for the vapour permeability, the Knudsen law was adopted to consider the water vapour diffusion through unsaturated pore network where only the water content forms on the pore surface by vapour adsorption. Accordingly, the following expression can be used to represent the vapour permeability such that:

$$
K_{\mathrm{v}}=D_{0} \cdot(1-S) /\left\{\tau \cdot\left[1+l_{\mathrm{m}} / 2\left(r_{\mathrm{m}}-t_{\mathrm{a}}\right)\right]\right\} \cdot\left[M_{\mathrm{w}} /(R \cdot T)\right]
$$


where, $D_{0}$ is the diffusivity of water vapour at free air $\left(\mathrm{m}^{2} / \mathrm{s}\right), S$ is the degree of saturation, $l_{\mathrm{m}}$ is the mean free path for water molecules $(\mathrm{m}), r_{\mathrm{m}}$ is the mean of unsaturated pore sizes $(\mathrm{m}), t_{\mathrm{a}}$ is the thickness of water layer on pore wall $(\mathrm{m})$.

To consider the effect of water entrapment on vapour desorption, a simple probabilistic approach [5] was used to determine the degree of saturation at drying condition, $S_{\mathrm{d}}$, such that:

$$
S_{\mathrm{d}}=S_{\mathrm{w}} \cdot\left[1-\ln \left(S_{\mathrm{w}}\right)\right]
$$

where, $S_{\mathrm{w}}$ is the degree of saturation at wetting condition, which can be derived based on pore size distribution using Eq. 3 such that:

$$
S_{\mathrm{w}}=\varnothing(r) / \varnothing_{\mathrm{t}}
$$

where, $\varnothing_{\mathrm{t}}$ is the total porosity, sum of gel and capillary pores.

\subsection{Chloride transport}

Chloride penetration, arose from both diffusion and convection, can be described by a modified diffusion-convection equation, considering the chloride binding, pore saturation, and humidity flux as a solvent velocity such that:

$$
\left(d C_{\mathrm{b}} / d C_{\mathrm{f}}+w_{\mathrm{e}}\right) \cdot\left(d C_{\mathrm{f}} / d t\right)=\operatorname{div}\left[\left(D_{\mathrm{e}} \cdot w_{\mathrm{e}}\right) \cdot \operatorname{grad}\left(C_{\mathrm{f}}\right)+w_{\mathrm{e}} \cdot C_{\mathrm{f}} \cdot D_{\mathrm{h}} \cdot \operatorname{grad}(h)\right]
$$

where, $C_{\mathrm{b}}$ is the concentration of bound chloride in hydrates $\left(\mathrm{kg} / \mathrm{m}^{3}\right), C_{\mathrm{f}}$ is the concentration of free chloride ion in pore solution $\left(\mathrm{kg} / \mathrm{m}^{3}\right), D_{\mathrm{e}}$ is the effective chloride diffusivity $\left(\mathrm{m}^{2} / \mathrm{s}\right), w_{\mathrm{e}}$ is the water filled porosity, $D_{\mathrm{h}}$ is the moisture diffusivity $\left(\mathrm{m}^{2} / \mathrm{s}\right)$, which can be obtained by incorporating liquid and vapour transport parameters such that:

$$
D_{\mathrm{h}}=\left[\left(K_{1} \cdot \rho_{\mathrm{w}} \cdot R \cdot T\right) /\left(M_{\mathrm{w}} \cdot h\right)+K_{\mathrm{v}} \cdot P_{0}\right] /(d w / d h)
$$

The binding capacity, $d C_{\mathrm{b}} / d C_{\mathrm{f}}$ [6], was obtained by applying the Langmuir isotherm such that:

$$
d C_{\mathrm{b}} / d C_{\mathrm{f}}=\alpha /\left[\left(1+\beta \cdot C_{\mathrm{f}}\right)^{2}\right]
$$

where, $\alpha$ and $\beta$ are the binding parameters of the Langmuir isotherm.

\subsection{Boundary condition}

The climatic boundary conditions were the relative humidity and chloride concentration. When concrete is submerged by high tidal, $99.5 \%$ and $0.5 \mathrm{M}$ respectively for relative humidity as a saturation state and for chloride concentration in sea water were assumed. 
Otherwise, $60 \%$ for relative humidity and zero concentration for chloride were set as the boundary conditions for drying state. As for the humidity flux at concrete surface, a convective boundary condition based on a mass transfer coefficient was used such as:

$$
D_{\mathrm{h}} \cdot \operatorname{grad}(h)=B_{\mathrm{h}} \cdot\left(h_{\mathrm{s}}-h_{\mathrm{en}}\right)
$$

Where, $B_{\mathrm{h}}$ is the mass transfer coefficient for relative humidity $(\mathrm{m} / \mathrm{s}), h_{\mathrm{s}}$ and $h_{\mathrm{en}}$ are the relative humidity at surface of concrete and environment, respectively. By considering the intermittent chloride exposure on the boundary condition, concentration flux of free chloride ions with moisture transfer induced ionic flux [7] was set as:

$$
D_{\mathrm{e}} \cdot \operatorname{grad}\left(C_{\mathrm{f}}\right)=B_{\mathrm{c}} \cdot\left(C_{\mathrm{s}}-C_{\mathrm{en}}\right)+C_{\mathrm{en}} \cdot D_{\mathrm{h}} \cdot \operatorname{grad}(h)
$$

Where, $B_{\mathrm{c}}$ is the transfer coefficient for chloride exposure $(\mathrm{m} / \mathrm{s}), \mathrm{C}_{\mathrm{s}}$ and $C_{\text {en }}$ are the chloride concentration at surface of concrete and environment, respectively. Before the tidal zone exposure, concrete was assumed to have zero concentration of chloride and initially saturated state.

As for the numerical procedure for coupled mass transport, the Crank-Nicholson method was used to approximate the non-linear equations with $1 \mathrm{~mm}$ for distance increment and 0.1 day for time increment. To enhance the numerical stability on the calculation, the Gauss-Seidel method was used for the iterative solution with a tolerance, $10^{-6}$.

\section{Result and discussion}

\subsection{Moisture distribution}

The spatial values for rates of moisture flow and resultant water contents through concrete depths are required prior to implement the chloride convection problem.

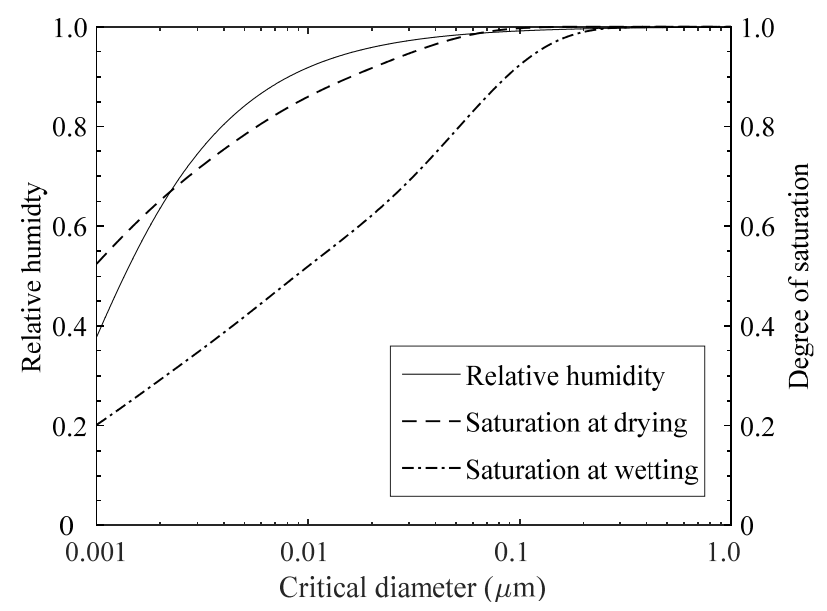

Fig. 1. Relation of relative humidity and degree of saturation under wet/dry conditions 
The relation of relative humidity and degree of saturation under wet/dry cycle can be determined using the Eq. 5 and 6. This implies that most of moisture flow occurs through gel and small capillary pores. Large capillary pores above $1.0 \mu \mathrm{m}$ can be ignored in analyzing the mass transport in unsaturated concrete since such high saturated state can be regarded as the regime of chloride diffusion. The effect of moisture entrapment during desorption process can be indicated by observing the difference between degree of saturations for drying and wetting. Thus, it should be noted that the different moisture properties between wet/dry conditions can occur and thus influence the behavior of chloride transport accordingly.

The moisture related chloride convection is largely dependent on the moisture diffusivity, $\mathrm{D}_{\mathrm{h}}$, which also dependent on the relative humidity, as shown in Fig. 2. As relative humidity increases, the rate of moisture flow decreases below about $20 \%$ humidity and then increases over the moisture level. This implies that moisture transport due to liquid permeation is more significant compared with that by vapour phase, which is dominant in low humidity condition. In particular, high water contents over $80 \%$ of relative humidity accelerate the moisture flow by Darcy's permeation.

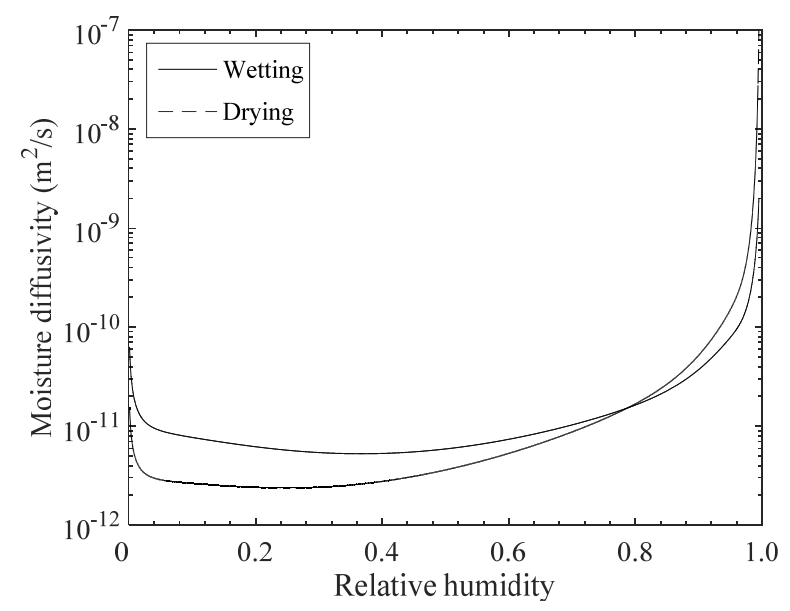

Fig. 2. Moisture diffusion coefficient dependent on relative humidity under wet/dry conditions

\subsection{Chloride transport in unsaturated concrete}

To assess the influence of drying period on rate of chloride penetration, 12 hours of wetting time per day and three different durations for drying were used to simulate 30 years of chloride concentration distribution, as shown in Fig. 3. As a result, increased dry duration promotes chloride transport under constant chloride diffusivity. This might be attributed to the fact that water supply during wetting cycle enhances the moisture gradient from the surface of concrete, which is more dominant in the case of concrete with low moisture level associated with longer period of drying. Thus, the rate of convective chloride penetration can be enhanced by moisture permeation coming from the wetting phase and propagates into the inner part of concrete. 


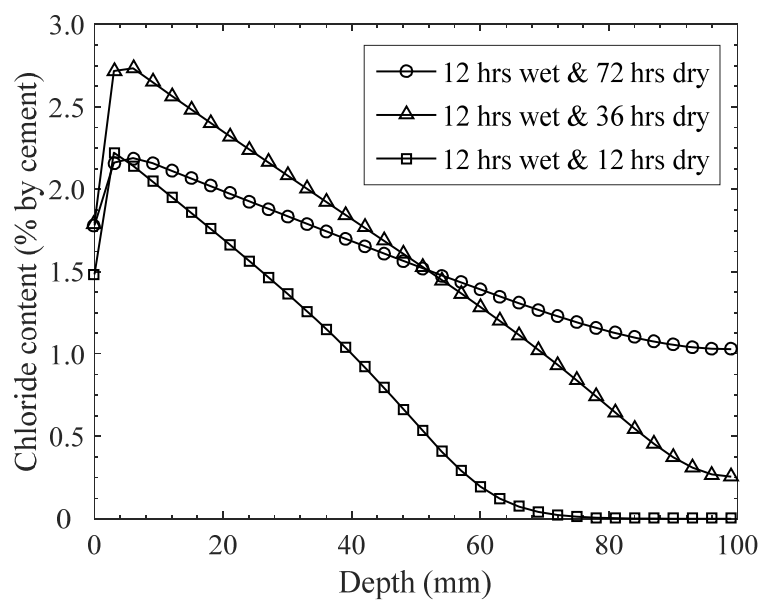

Fig. 3. Chloride concentration profiles varying with dry durations on 30 years of chloride exposure

To assess the effect of convection phenomena on the chloride concentration front, a single diffusion analysis at fully saturated concrete was compared with the case of chloride diffusion-convection, as given in Fig. 4. The surface chloride content at complete saturation shows higher value, accounting for $1.65 \%$, compared with the case of partial saturation, $1.48 \%$, probably due to the limited duration of chloride exposure. Despite the low concentration at surface, peak values, made by the repeated wet and dry, were observed near the surface and increase with time. This can also promote the rate of chloride penetration by enhanced concentration gradient from the surface and thus diffusion process. Also, the moisture flow containing chloride ion moves toward inner concrete depth which is more predominant than flow to the surface. Consequently, the rate of chloride penetration, arose from the coupled action of enhanced diffusion and convection into concrete depth, may surpass the one with diffusion only, irrespective of exposure time. Thus, it is inferred that chloride transport analysis on intermittent mass exposure should encompass the chloride convection, capable of reflecting the effects of thermodynamic equilibrium on water sorption and desorption together with humidity dependent moisture permeability.

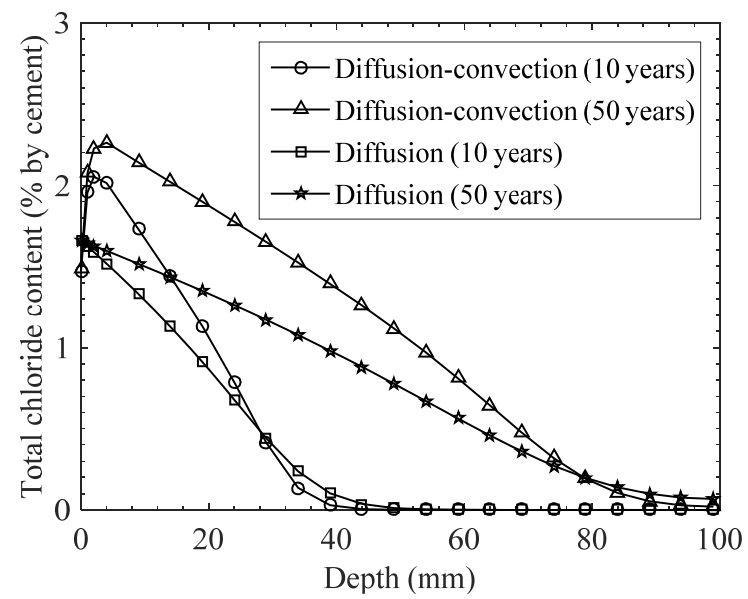

Fig. 4. Chloride concentration profiles in the presence and absence of convection phenomena 


\section{Conclusions}

The present paper focused on investigating the chloride penetration in unsaturated concrete by using the mathematical models in terms of coupled moisture and chloride transport. From this work, the following conclusions were made:

(1) Due to the moisture entrapment, the degree of saturation during the dying cycle shows always higher value, compared with the adsorption process. Moisture diffusivity from the calculation shows high dependence on the liquid permeability, particularly over about $80 \%$ humidity condition. Those resultant moisture properties under wet/dry cycle can affect the chloride transport in partially saturated concrete.

(2) From the calculation, the rate of chloride penetration in the presence of moisture flux exceed that with diffusion only, irrespective of chloride exposure time. This was mainly due to (a) enhanced chloride concentration gradient from the surface of concrete by repeated wet/dry durations and (b) moisture permeation from the surface of concrete during wet cycle, which in turn promotes chloride convection velocity toward concrete depth.

\section{Acknowledgements}

This research was supported by Basic Science Research Program through the National Research Foundation of Korea (NRF) funded by the Ministry of Science, ICT \& Future Planning (No. 2015R1A5A1037548)

\section{References}

1. C.L. Page, Nature 256, 514 (1975)

2. A. Boddy, E. Bentz, M.D.A. Thomas, R.D. Hooton, Cem. Concr. Res. 29, 6 (1999)

3. Y. Zhang, W.L. Jin, ACI. Mater. J. 108, 5 (2011)

4. F. A. Dullien, Porous media : fluid transport and pore structure (Academic Press, 2009)

5. R. Chaube, T. Kishi, K. Maekawa, Modelling of concrete performance: Hydration, microstructure and mass transport (CRC Press, 2005)

6. B. Martın-Pérez, H. Zibara, R.D. Hooton, M.D.A. Thomas, Cem. Concr. Res. 30, 8 (2000) (2000).

7. A.V. Saetta, R.V. Scotta, R.V. Vitaliani, ACI. Mater. J. 90, 5 (1993) 